\title{
Supramolecular Formation of Mono- and Bis-Modified Pyrene Cavitands and Their Fluorogenic Metal Sensory System in an Aqueous Solution
}

\author{
Yoshihiko KONDO, Yoshiaki YAMAZAKI, Norio NASHIROZAWA, \\ Miyuki NARITA and Fumio HAMADA* \\ *Department of Materials-process Engineering and Applied Chemistry for Environments, \\ Faculty of Engineering Resource Science, Akita University, Tegata Akita 010-8502, Japan \\ E-mail : hamada@ipc.akita-u.ac.jp
}

\begin{abstract}
In order to study the supramolecular formations of guest-responsive cavitand derivatives in aqueous solution, synthesis of water-soluble fluorogenic cavitands, which are modified with mono- and bis-pyrene units ( 1 and 2, respectively), and their metal sensing abilities have been investigated. Compound 2 showed monomer and excimer emissions in both an organic and aqueous, which was contained a 10 vol.\% DMF, solution, whereas compound 1 indicated these two emissions in only aqueous solution. The fluorescence spectral patterns of compounds 1 and 2 were changed depending on DMF concentrations in an aqueous solution. The extent of the excimer emission of 2 was the highest in a 50 vol.\% DMF, whereas drastic decrease of this excimer emission was observed in over 60 vol.\% DMF. On the other hand, compound 1 showed the highest excimer emission intensity between 10-30 vol.\% DMF and middle emission was recognized in $30 \mathrm{vol} \%$ DMF. Finally, in over 50 vol. \% DMF, no excimer emission of 1 was observed. The movements of the appended units of these compounds in various DMF concentrations were studied by the fluorescence and UV spectra and MM2-minimized structures. A ratio of excimer and monomer emission intensities of 1 and 2 were varied in 10-40 vol.\% and 10-50 vol.\% DMF contents in water, respectively. The UV spectra patterns of 1 or 2 were different between in $10-40$ vol. $\%, 50$ vol. $\%$ and over 60 vol. $\%$ or $10-50$ vol. $\%, 60$ vol. $\%$ and over 70 vol.\% DMF aqueous solutions, respectively. The variations of fluorescence and UV spectra suggested that compounds 1 and 2 formed association dimer in 10-40 vol.\% and 10-50 vol.\% DMF aqueous solutions, respectively, and the canceling of these dimer formations was observed with increasing DMF content or metal concentration. Furthermore, fluorescent spectral changes and MM2minimized structures suggested that the association dimer of 2 , which formed one pair pyrene excimer in 10 vol.\% DMF aqueous solution, was transformed into different configuration of association dimer making plural pyrene excimer pairs in 20-50 vol.\% DMF aqueous solutions. In order to evaluate the metal sensing abilities of 1 and 2 in a 10 vol.\% DMF aqueous solution, the ratio of decrement of an intensity of excimer emission with an addition of metal cation was used as a detecting parameter. Compounds 1 and 2 exhibited the highest sensing abilities for $\mathrm{Na}^{2+}$ and $\mathrm{Co}^{2+}$, respectively.
\end{abstract}

Key Words : Cavitand, Pyrene, Metal sensing, Supramolecular formation

\section{INTRODUCTION}

Macrocyclic host molecules such as cyclodextrins, calixarenes and cavitands have attracted interest as an enzyme model or supramolecular compounds, because these hosts can accommodate a variety of guests such as organic molecules or metals in their cavity. ${ }^{1-2}$ The modifications of these macrocyclic molecules with spectroscopically active unit result in a new function which is hardly to show for native hosts. ${ }^{3}$ Our primary focus is in the design of luminescent active host-guest complexes as sensor and molecular probe. During a last decade, we have studied organic molecular sensing system based on fluorescent active cyclodextrins such as bis-dansyl modified cyclodextrin analogs in an aqueous solution. ${ }^{4,5}$ The mechanism of the host-guest complexation is going on an induced-fit type of complex behavior, in which the appended fluorogenic moieties are moved out from the inside of the cyclodextrin cavity toward the outside with a decrement of the fluorescence intensity, because it is well known that the dansyl moiety is very sensitive to the polarity of an environment. In our previous studies on a metal cation detecting by macrocyclic hosts consisted of benzene rings such as calix[4]arene analogs, we have reported metal sensing by dansyl modified thiacalix[4]arene analogs in an aqueous solution, ${ }^{6,7}$ in which the dansyl unit also 
moves out from the calixarene cavity to the outside, which is very polar environment. This calixarene system also exhibits very high sensing for metal, going on an induced-fit type of complex behavior as shown in the case of cyclodextrin derivatives. For further extension of our work, we attempted to synthesize new fluorogenic host molecules composed of benzene units based on cavitand. The synthesis of cavitand has been reported by Cram and co-workers ${ }^{8}$, and then many analogs of cavitand have been prepared to study their host-guest complexation properties in an organic solvent or at a solid state. ${ }^{9-26}$ A couple years ago, we have reported selective chloromethylation of cavitand and the metal binding property of aza-crown-modified cavitands in an organic solvent based on bis-chloromethyl cavitand. ${ }^{27}$ In order to continue our study on cavitand chemistry, mono- and bis-pyrene-modified cavitands ( 1 and 2, respectively) have been synthesized as watersoluble fluorogenic hosts from mono- and bis-chloromethylated cavitands. ${ }^{28}$ In this contribution, we would like to describe the association dimer formation and the host-guest binding behavior of the host compounds. Hosts 1 and 2 are exiting as an association dimer in a 10 vol.\% DMF aqueous solution, in which these hosts showed the metal detecting ability by the fluorescence spectral changes upon a metal addition.

\section{Experimental}

\subsection{Preparations of compounds 1 and 2}

A mixture of bis-chloromethylcavitand $27(100 \mathrm{mg}, 0.145 \mathrm{mmol})$ and sodium pyrenebutylate $(119 \mathrm{mg}, 0.348 \mathrm{mmol})$ in $15 \mathrm{~mL}$ of DMF was stirred at room temperature for $20 \mathrm{~h}$. The reaction mixture was concentrated in vacuo, and the product was extracted with chloroform. The organic phase was washed with water, dried over anhydrous $\mathrm{Na}_{2} \mathrm{SO}_{4}$, and evaporated. The crude was dissolved on $5 \mathrm{~mL}$ of carbon tetrachloride, and the carbon tetrachloride soluble fraction was applied to a column chromatography (Lobar column Lichroprep Si60). Stepwise elution using $300 \mathrm{~mL}$ of 9 vol. $\%, 10$ vol. $\%, 11$ vol. $\%, 13$ vol. $\%, 14$ vol. $\%, 17$ vol $\%$, and 20 vol.\% ethylacetate/n-hexane solution, and $300 \mathrm{~mL}$ of $25 \mathrm{vol} . \%$ ethylacetate/n-hexane solution was applied to obtain bis-pyrenebutylate cavitand 2 (yeild: 48\%). Compound 1 was prepared by the same procedure as compound 2 using mono-chloromethylcavitand 27 (yeild: 42\%).

Compound 1: $\mathrm{R}_{\mathrm{f}} 0.63$ (n-hexane-AcOEt 2:1 by volume, TLC: silica gel $\left.60 \mathrm{~F}_{254}\right) .{ }^{1} \mathrm{H}-\mathrm{NMR}$ spectra $\left(\mathrm{CDCl}_{3}, 300 \mathrm{MHz}\right): \delta=1.73$ $\left(12 \mathrm{H}, \mathrm{d}, \mathrm{J}=7.5 \mathrm{~Hz},-\mathrm{CHCH}_{3}\right.$ in cavitand), 2.17-2.26 $(4 \mathrm{H}, \mathrm{br}$, $-\mathrm{COCH}_{2} \mathrm{CH}_{2} \underline{\mathrm{CH}}_{2}-\mathrm{Ar}$ in pyrenebutylate), $3.40(2 \mathrm{H}, \mathrm{t}, \mathrm{J}=7.5 \mathrm{~Hz}$, $-\mathrm{COCH}_{2} \mathrm{CH}_{2} \mathrm{CH}_{2}-\mathrm{Ar}$ in pyrenebutylate), $4.20(2 \mathrm{H}, \mathrm{d}, \mathrm{J}=7.2 \mathrm{~Hz}$, inner of $\mathrm{CH}_{2}$ in cavitand), $4.33\left(2 \mathrm{H}, \mathrm{d}, \mathrm{J}=7.2 \mathrm{~Hz}\right.$, inner of $\mathrm{CH}_{2}$ in cavitand), 4.93 ( $4 \mathrm{H}$, quintet, $\mathrm{J}=7.4 \mathrm{~Hz},-\mathrm{CHCH}_{3}$ in cavitand), 5.07 $\left(2 \mathrm{H}, \mathrm{s},-\mathrm{OCH}_{2}-\mathrm{Ar}\right.$ at upper rim in cavitand $), 5.66(2 \mathrm{H}, \mathrm{d}, \mathrm{J}=7.5 \mathrm{~Hz}$, outer of $\mathrm{CH}_{2}$ in cavitand), $5.70\left(2 \mathrm{H}, \mathrm{d}, \mathrm{J}=7.2 \mathrm{~Hz}\right.$, outer of $\mathrm{CH}_{2}$ in cavitand), 6.21 (2H, s, Ar-H at upper rim in cavitand), $6.47(1 \mathrm{H}$, $\mathrm{s}, \mathrm{Ar}-\mathrm{H}$ at upper rim in cavitand), $7.18(3 \mathrm{H}, \mathrm{s}, \mathrm{Ar}-\mathrm{H}$ at lower rim in cavitand), 7.79-8.28 (9H, $\mathrm{m}, \mathrm{Ar}-\mathrm{H}$ in pyrenebutylate). Calcd. for $\mathrm{C}_{57} \mathrm{H}_{48} \mathrm{O}_{10} \cdot 2 \mathrm{H}_{2} \mathrm{O}$ : C, $73.69 ; \mathrm{H} 5.64 \%$. Found: C, 73.82; H 5.54 \%. MS(FAB) $[\mathrm{m} / \mathrm{z}]: 892\left([\mathrm{M}]^{+}\right)$.

Compound 2: $\mathrm{R}_{\mathrm{f}} \quad 0.59$ ( $n$-hexane-AcOEt 2:1 by volume, TLC: silica gel $\left.60 \mathrm{~F}_{254}\right)$. ${ }^{1} \mathrm{H}-\mathrm{NMR}$ spectra $\left(\mathrm{CDCl}_{3}, 300 \mathrm{MHz}\right): \delta=$ $1.73\left(12 \mathrm{H}, \mathrm{d}, \mathrm{J}=7.5 \mathrm{~Hz},-\mathrm{CHCH}_{3}\right.$ in cavitand), $2.16(8 \mathrm{H}, \mathrm{s}$, $-\mathrm{COCH}_{2} \underline{\mathrm{CH}}_{2} \underline{\mathrm{CH}}_{2}-\mathrm{Ar}$ in pyrenebutylate), $3.33(4 \mathrm{H}, \mathrm{t}, \mathrm{J}=6.6 \mathrm{~Hz}$, $-\mathrm{COCH}_{2} \mathrm{CH}_{2} \mathrm{CH}_{2}-\mathrm{Ar}$ in pyrenebutylate), $4.09(4 \mathrm{H}, \mathrm{d}, \mathrm{J}=6.9 \mathrm{~Hz}$, inner of $\mathrm{CH}_{2}$ in cavitand), $4.90\left(4 \mathrm{H}\right.$, quintet, $\mathrm{J}=7.2 \mathrm{~Hz},-\mathrm{CHCH}_{3}$ in cavitand), $5.06\left(4 \mathrm{H}, \mathrm{s},-\mathrm{OCH}_{2}-\mathrm{Ar}\right.$ at upper rim in cavitand), 5.61 $\left(4 \mathrm{H}, \mathrm{d}, \mathrm{J}=7.2 \mathrm{~Hz}\right.$, outer of $\mathrm{CH}_{2}$ in cavitand), $5.94(2 \mathrm{H}, \mathrm{s}, \mathrm{Ar}-\mathrm{H}$ at upper rim in cavitand), $7.11(2 \mathrm{H}, \mathrm{s}$, Ar- $\mathrm{H}$ at lower rim in cavitand), 7.19 (2H, s, Ar-H at lower rim in cavitand), 7.69-8.21 (18H, m, Ar-H in pyrenebutylate). Calcd. for $\mathrm{C}_{78} \mathrm{H}_{64} \mathrm{O}_{12} \cdot \mathrm{H}_{2} \mathrm{O}: \mathrm{C}$, 77.34; H, 5.49\%. Found: C, 77.20; H, 5.72\%. MS(FAB)[m/z]: $1192\left([\mathrm{M}]^{+}\right)$.

\subsection{Measurements}

Fluorescence and ultraviolet spectra were measured at $25^{\circ} \mathrm{C}$ with a Perkin-Elmer LS 40B Fluorescence spectrometer and a Perkin-Elmer Lambad 40 UV-VIS spectraophotometer, respectively. For the fluorescence measurements, the excitation wavelength of the fluorescence spectra was $355 \mathrm{~nm}$ and excitation and emission slits were $5 \mathrm{~nm}$. A DMF aqueous solution (10 vol.\%) was used as solvent for hosts for the spectroscopic measurements because the solubility of the hosts ( 1 and 2$)$ in pure water was poor. Ten microliters of metal cations in pure water were injected into a 10 vol. \% DMF aqueous solution of the hosts $(2.5 \mathrm{~mL})$ to make a sample solution with a host concentration of $5.0 \times 10^{-7} \mathrm{M}$ and metal nitrate concentration of $1.0 \mathrm{mM}$.

\subsection{Energy-minimized structures}

Energy-minimized structures of 1 and 2 were calculated by molecular mechanics using MM2 in CS Chem 3D. The parameters of MM2 are improved ones obtained from studies by Allinger ${ }^{29}$ based on the TINKER system researched by Ponder. ${ }^{30}$

\subsection{Determination of binding constants}

The binding constants of 1 and 2 for several guests were obtained from the guest-induced fluorescence variations around $465 \mathrm{~nm}$ by employing a Benesi-Hildbrand-type equation, as reported previously.?

\section{Results and discussion}

\subsection{Fluorescence and UV spectra of 1 and 2 in various aqueous-DMF solutions.}

Figure 1 shows the fluorescence spectra of 1 and 2 in a $\mathrm{CHCl}_{3}$. The fluorescence spectra of 2 exhibit monomer and excimer emission, whereas 1 shows only monomer emission. This means
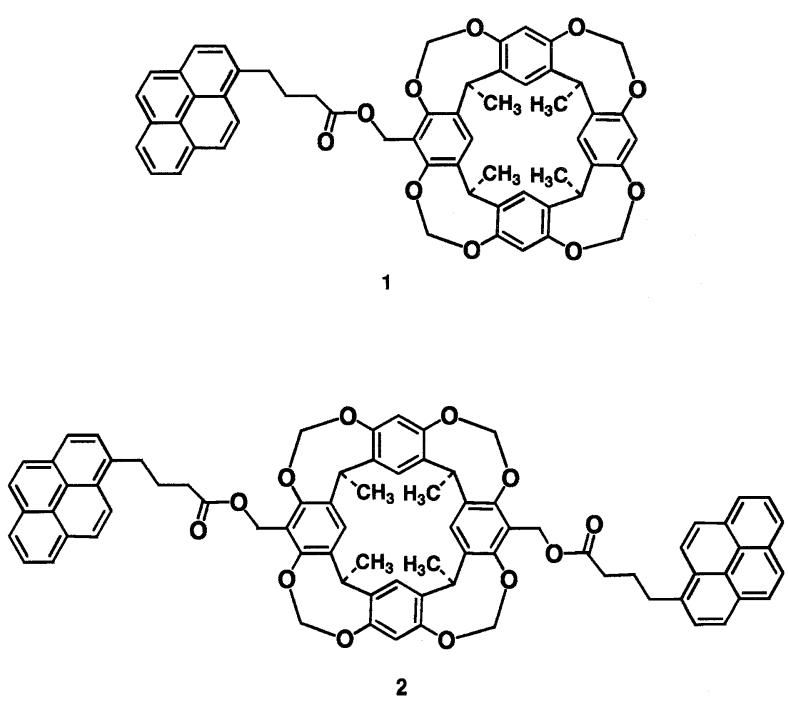

Scheme 1 Structures of 1 and 2 . 
that the pyrene excimer of 2 in organic solvent such as $\mathrm{CHCl}_{3}$ derives from intramolecular interaction not intermolecular interaction.

The fluorescence spectra of 1 and 2 in various DMF aqueous Gsolutions show different patterns as depicted in Figures 2 and 3a, respectively. Ranging from 10-30 vol.\% DMF, the spectra patterns of 1 are almost same. The fluorescence intensity in excimer emission of 1 in 40 vol.\% DMF decreases, moreover, in over 50 vol.\% DMF, its excimer emissions do not appear and its monomer emissions are given larger intensities than those of 1 in $10-40$ vol.\% DMF. In this case, the pyrene excimer in a $10-40 \mathrm{vol} . \%$ DMF aqueous solutions should be produced by intermolecular interaction, namely, compound 1 forms the association dimer in $10-40$ vol.\% DMF aqueous solution. Although, compound 1 may exist as monomer in over 50 vol.\% DMF aqueous solution. On the other hand, the spectra patterns of 2 are different from those of 1.

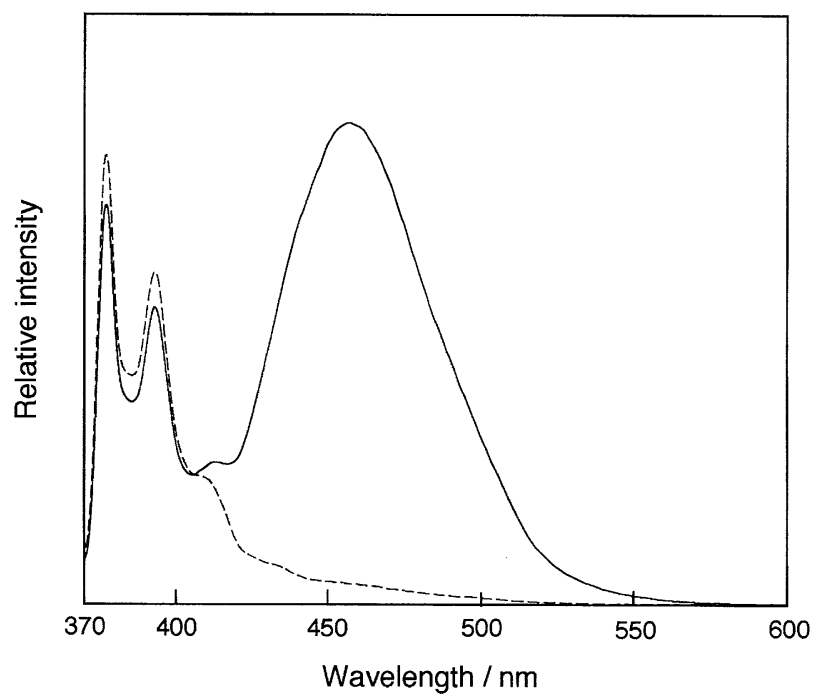

Figure 1 Fluorescence spectra of $1(--)$ and $2(-)\left(1.0 \times 10^{-6} \mathrm{M}\right.$, $\left.25^{\circ} \mathrm{C}\right)$ in $\mathrm{CHCl}_{3}$ solution.

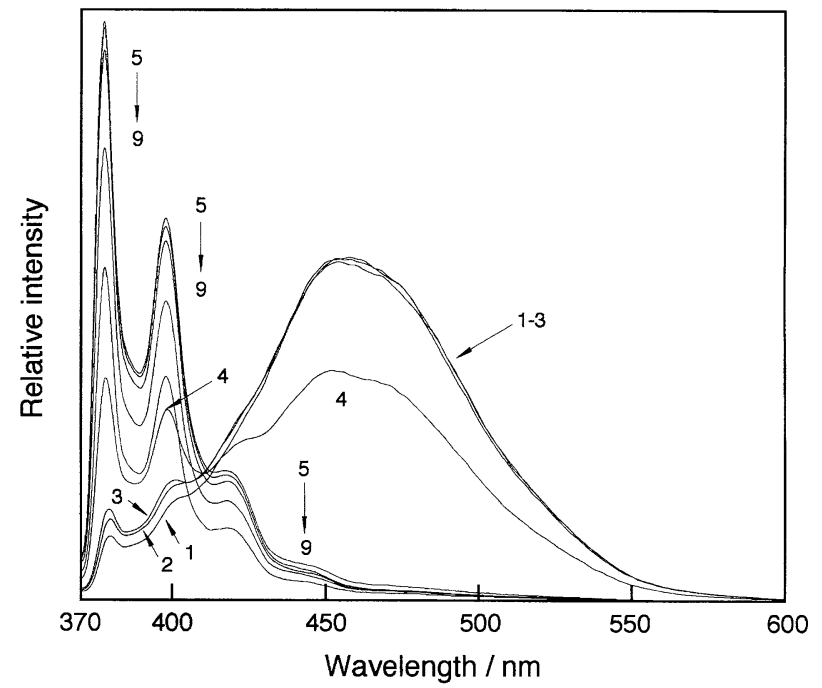

Figure 2 Fluorescence spectra of $1\left(5.0 \times 10^{-7} \mathrm{M}, 25^{\circ} \mathrm{C}\right)$ in various ratio of DMF aqueous solution (1: 10,2:20,3:30,4:40,5:50,6: 60, 7: 70, 8: 80, 9: 90 vol.\%).
In the spectra patterns of 2, the increment of DMF content leads enhancement of its excimer emission in $10-50$ vol.\% DMF. In contrast, the large extent in a decrement of excimer emission of 2 in $60-90$ vol.\% DMF was observed, however, its excimer mission does not disappear. These facts suggest that the pyrene excimer of 2 is produced in two different ways depending on the ratio of DMF contents, probably, one is produced by the intermolecular interaction and another one is produced by intramoleculer interaction. In order to decide whether the pyrene excimer of 2 drives from intermolecular or intramolecular interactions, a ratio of monomer versus excimer emissions of 2 in various of DMF contents in an aqueous solution is figured out, as shown in Figure $3 \mathrm{~b}$. The values $I_{e x} / I_{m I}$ and $I_{e x} / I_{m 2}$ were used as parameters, where $I_{m I}$ and $I_{m 2}$, and $I_{e x}$

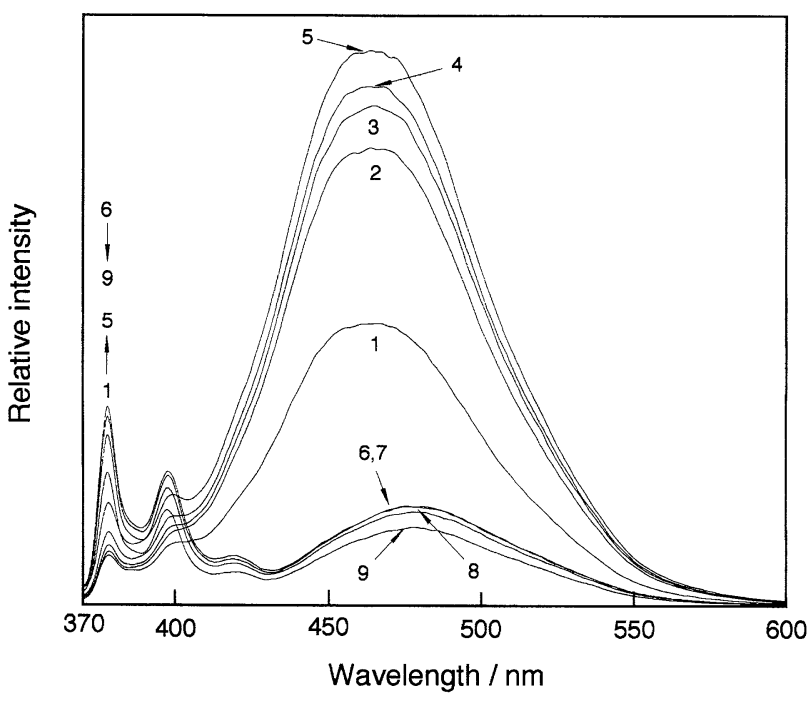

Figure 3a Fluorescence spectra of $1\left(5.0 \times 10^{-7} \mathrm{M}, 25^{\circ} \mathrm{C}\right)$ in various ratio of DMF aqueous solution (1: 10,2:20,3:30,4:40, 5: 50,6: 60, 7: 70, 8: 80, 9: 90 vol.\%).

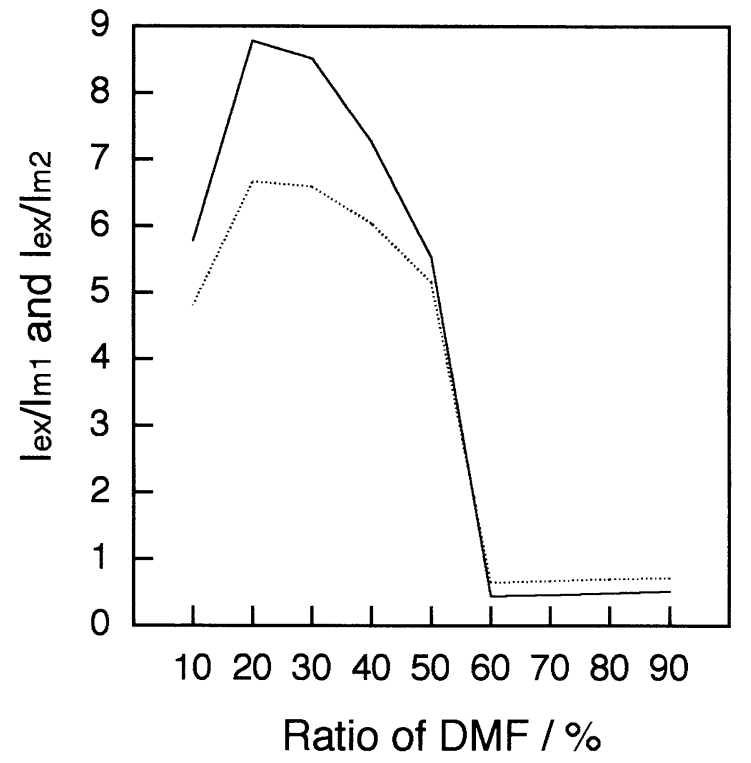

Figure $3 \mathrm{~b}$ Parameters of $1_{\text {ex }}$ versus Im of 2 in various ratio of DMF aqueous solution $\left(\mathrm{I}_{\mathrm{ex}} / \mathrm{I}_{\mathrm{ml}}:-, \mathrm{I}_{\mathrm{ex}} / \mathrm{I}_{\mathrm{m} 2}: \cdots \cdots\right)$. 
are intensities of monomer emissions at 380 and $398 \mathrm{~nm}$ and excimer emission at $465 \mathrm{~nm}$, respectively. The values $I_{e x} / I_{m l}$ and $I_{e x} / I_{m 2}$ of 2 were changed in 10-50 vol.\% DMF, and these values were regular in over 60 vol. $\%$ DMF. These results mean that the pyrene excimer in $10-50$ vol. $\%$ DMF is caused by intermolecular interaction. In over $60 \mathrm{vol} \% \mathrm{DMF}$ aqueous solution, it is indicated that the emission of pyrene excimer is presumably due to intermolecular interaction. Therefore, compound 2 is seemed to form the association dimer in 10-50 vol.\% DMF aqueous solution.

Figures 4 and 5 show the UV spectra of 1 and 2 in various aqueous-DMF solutions. In the spectra of 1 , the patterns in 10-40 vol.\% DMF are similar, although, those in over $50 \mathrm{vol} . \% \mathrm{DMF}$ are different. In the spectra of 2 , the patterns in $10-50$ vol. $\%, 60$ vol. $\%$ and over 70 vol.\% DMF are dissimilar. It is suggested that the

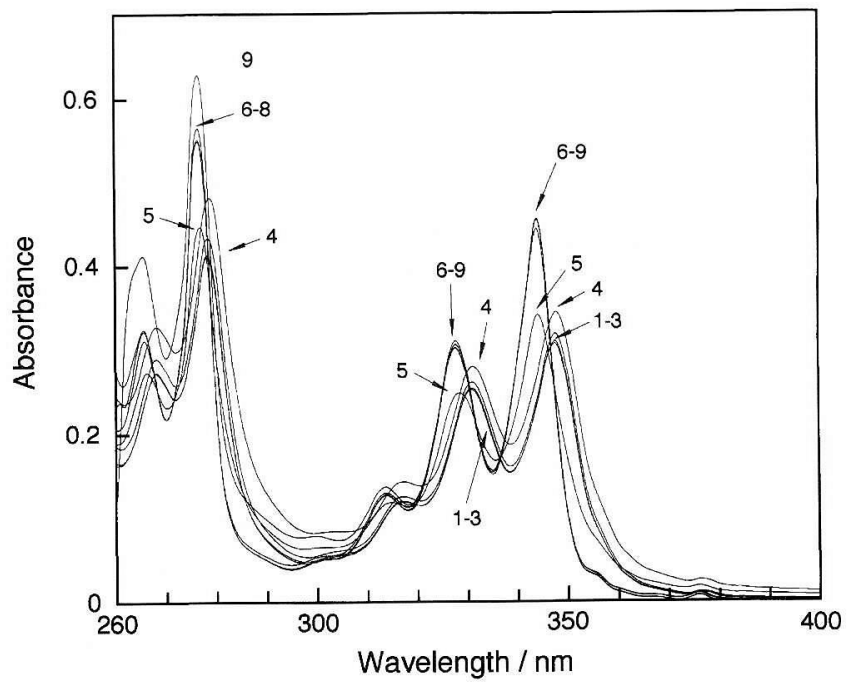

Figure 4 Absorption spectra of $1\left(1.0 \times 10^{-5} \mathrm{M}, 25^{\circ} \mathrm{C}\right)$ in various ratio of DMF aqueous solution (1: 10, 2: 20, 3: 30, 4: 40, 5: 50,6:60, 7: $70,8: 80,9: 90$ vol.\%).

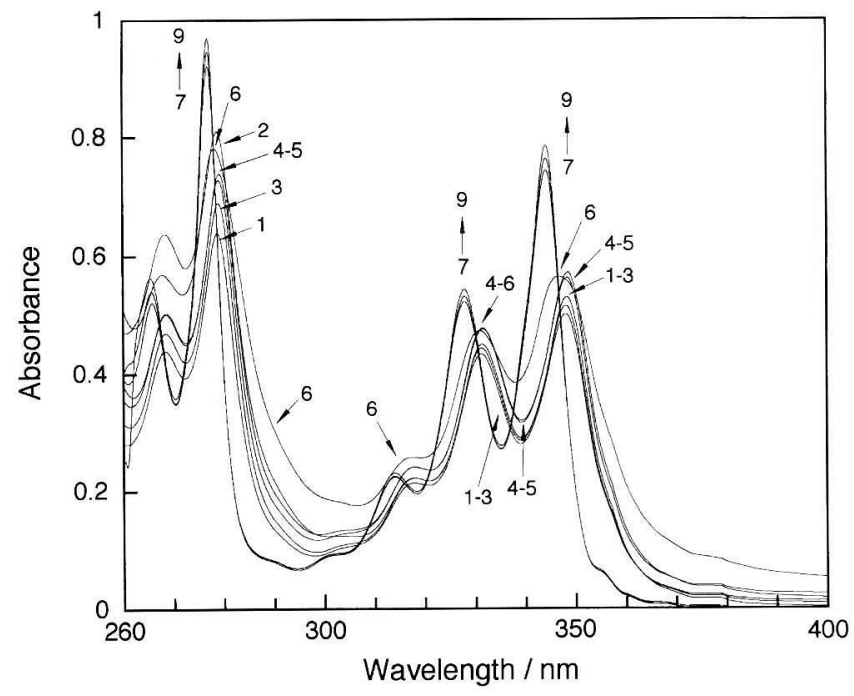

Figure 5 Absorption spectra of $2\left(1.0 \times 10^{-5} \mathrm{M}, 25^{\circ} \mathrm{C}\right)$ in various ratio of DMF aqueous solution (1: 10, 2: 20, 3: 30, 4: 40, 5: 50, 6: 60, 7: $70,8: 80,9: 90$ vol.\%). formation of the appended moieties of 1 or 2 is different in each concentration of DMF. The variations of these UV spectra are indentical to the fluorescent spectral changes as mentioned above. Therefore, the UV spectral changes support the transformation of the pyrene excimer of 1 and 2 , in which the association dimer of 1 and 2 is occurring between $10-40$ vol.\% and 10-50\% DMF, respectively.

In order to examine the formations of association dimer of 1 and 2, MM2-minimized structures of these hosts were calculated, as shown in Scheme 2. In this system, it is seemed that the pyrene moiety of 1 and 2 in 10 vol.\% DMF aqueous solution is included into another cavitand cavity due to the hydrophobic interaction between the pyrene moiety and cavitand cavity similar to the case of cyclodextrin derivative. ${ }^{31}$ With the increasing of DMF content in an aqueous solution as a solvent, the pyrene excimer of 1 completely is cancelled by the weakening of the hydrophobic interaction. On the other hand, the association dimer formation of 2 is altered in various ways with the increment of DMF content in an aqueous solution, in which the pyrene moieties form strong excimer formation in 10 vol.\% DMF and, in 20-50 vol.\% DMF. Scheme 3 illustrates the movement of the pyrene units with increase of DMF content in water. Furthermore, in over 60 vol.\% DMF, the formation of the pyrene excimer of 2 transforms intramolecule with canceling the association dimer.

Figures 6 and 7 show the fluorescent spectra changes of 1 and 2 in the presence and absence of $\mathrm{Na}^{+}$in a $10 \mathrm{vol} . \%$ DMF aqueous solution, respectively. The fluorescence spectra of 1 and 2 are

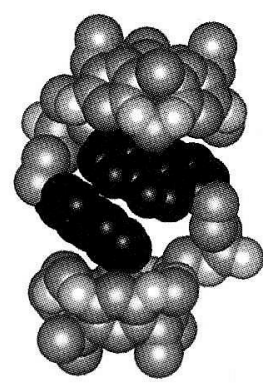

a

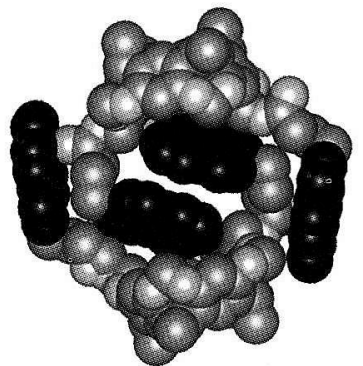

b
Scheme 2 Speculated structures of 1 (a) and 2 (b) obtained from MM2minimized space-filling in a $10 \mathrm{vol} . \% \mathrm{DMF}$ aqueous solution.

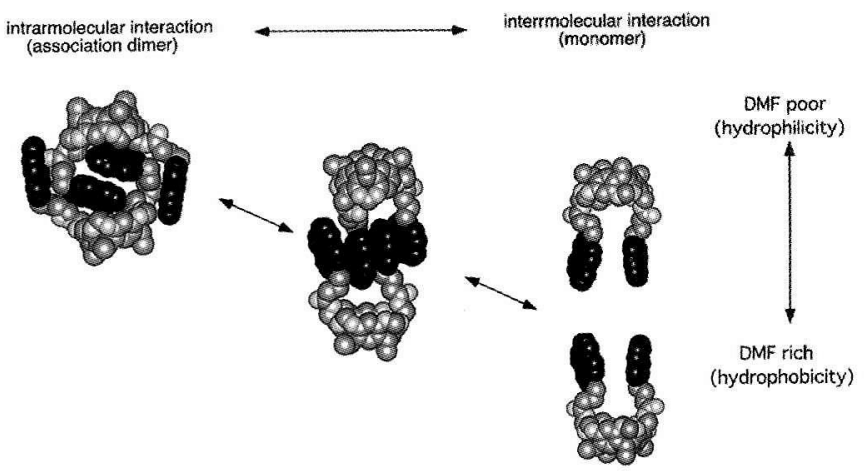

Scheme 3 Estimated transformation from association dimer to monomer of 2 in various DMF content of aqueous solutions. 
composed of almost pure excimer emission with a peak around $465 \mathrm{~nm}$, and the excimer fluorescence intensity decreases with increasing metal cation concentration. The excimer fluorescent intensity decrement suggests that the pyrene excimer formation is canceled. When a metal cation was added to the solutions of 1 and 2 , the metal cation was probably introduced into the cavitand cavity, because we have already reported that native cavitand can make host-guest complexation with metal cation. ${ }^{27}$ Accordingly, the metal binding mechanisms by these compounds seems to be illustrated as in Scheme 4. To examine a quenching effect of metal cations for fluorescence spectra of 1 and 2, the sensing parameter values were obtained in the presence of $\mathrm{Co}^{2+}$. The $\Delta I$ was used as a sensing parameter value. Here $\Delta I$ is $I^{0}-I$, where $I^{0}$ is the fluores-

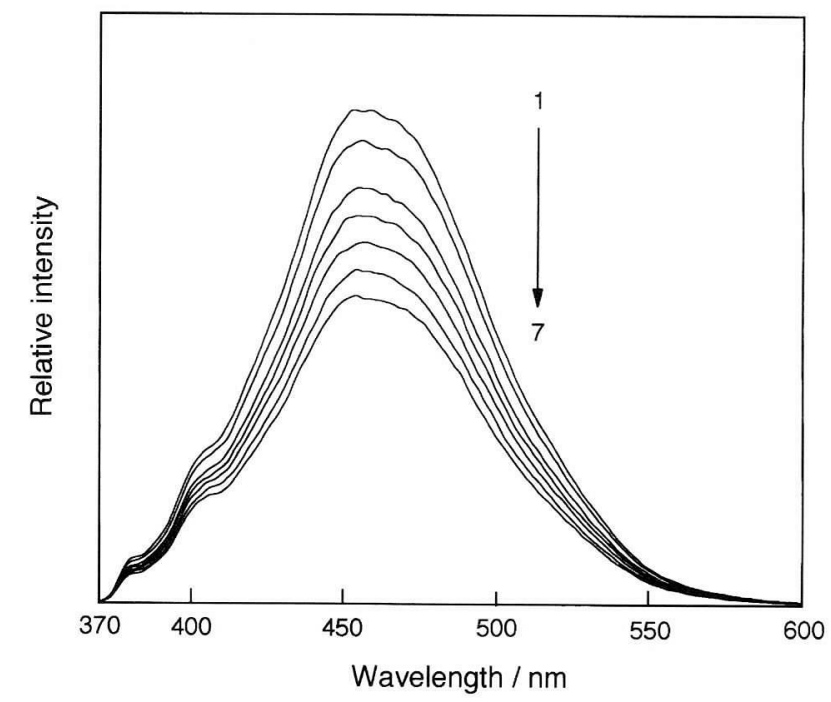

Figure 6 Fluorescence spectra of $1\left(5.0 \times 10^{-7} \mathrm{M}, 25^{\circ} \mathrm{C}\right)$ in a 10 vol.\% DMF aqueous solution with various concentrations of $\mathrm{Na}^{+}(1: 0$, 2: $1.0 \times 10^{-4},: 3.0 \times 10^{-4}, 4: 6.0 \times 10^{-4}, 5: 1.0 \times 10^{-3}, 6: 1.5 \times 10^{-3}, 7:$ $\left.2.1 \times 10^{-3} \mathrm{M}\right)$.

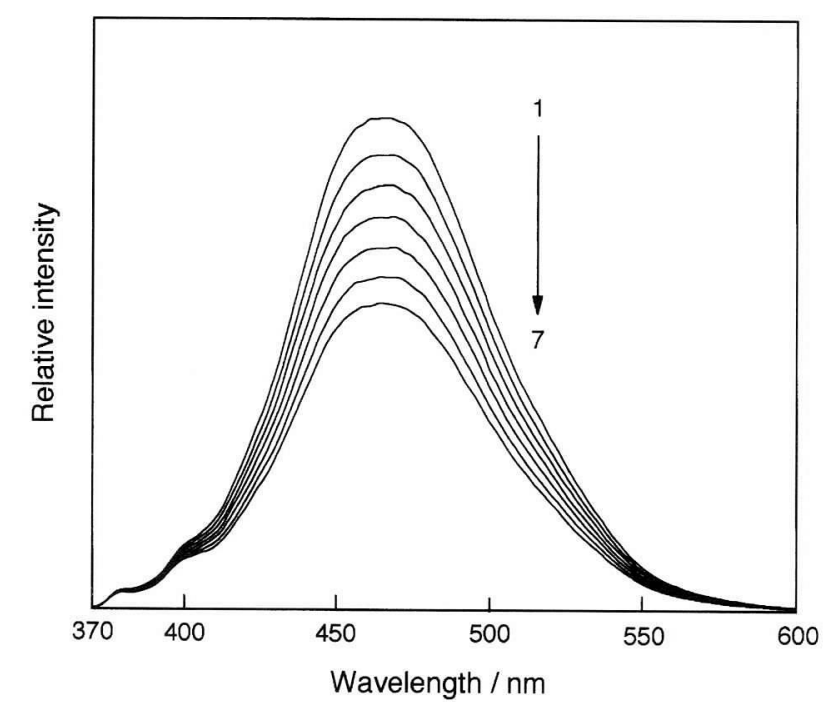

Figure 7 Fluorescence spectra of $2\left(5.0 \times 10^{-7} \mathrm{M}, 25^{\circ} \mathrm{C}\right)$ in a 10 vol.\% DMF aqueous solution with various concentrations of $\mathrm{Na}^{+}(1: 0$, 2: $1.0 \times 10^{-4}, 3: 3.0 \times 10^{-4}, 4: 6.0 \times 10^{-4}, 5: 1.0 \times 10^{-3}, 6: 1.5 \times 10^{-3}, 7$ : $\left.2.1 \times 10^{-3} \mathrm{M}\right)$ cence intensity at $465 \mathrm{~nm}$ for the host alone, and I is the fluorescence intensity at $465 \mathrm{~nm}$ for a complex with $\mathrm{Co}^{2+}$. Figure 8 shows the parameter values when the concentrations of $\mathrm{Co}^{2+}$ were ranging from $10^{-4} \mathrm{M}$ to $4.42 \times 10^{-3} \mathrm{M}$. The parameter values are going up to 0.340 , of which the value is constant when the concentration is up to $2.77 \times 10^{-3} \mathrm{M}$, and then the values are increased again. These results suggest that no quenching by metal cations for the fluorescent intensity is existing.

\subsection{Metal sensing abilities of 1 and 2}

The extent of variation of the fluorescence intensity of 1 and 2 depends on the nature of a metal cation, even at low concentration; therefore, these compounds can be used to be sensing molecule. To display the sensing abilities of 1 and 2 , the $\Delta I$ was used as a sensitivity parameter. Figure 9 shows the sensing parameters of 1
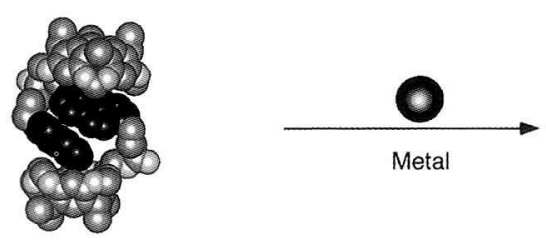

a
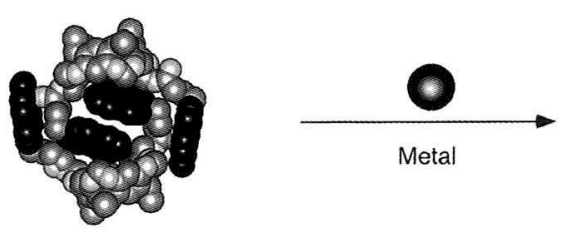

b
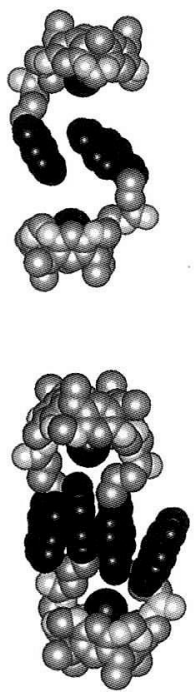

Scheme 4 Speculated mechanisms on the host-guest complexation of 1 (a) and 2 (b) in a 10 vol.\% DMF aqueous solution.

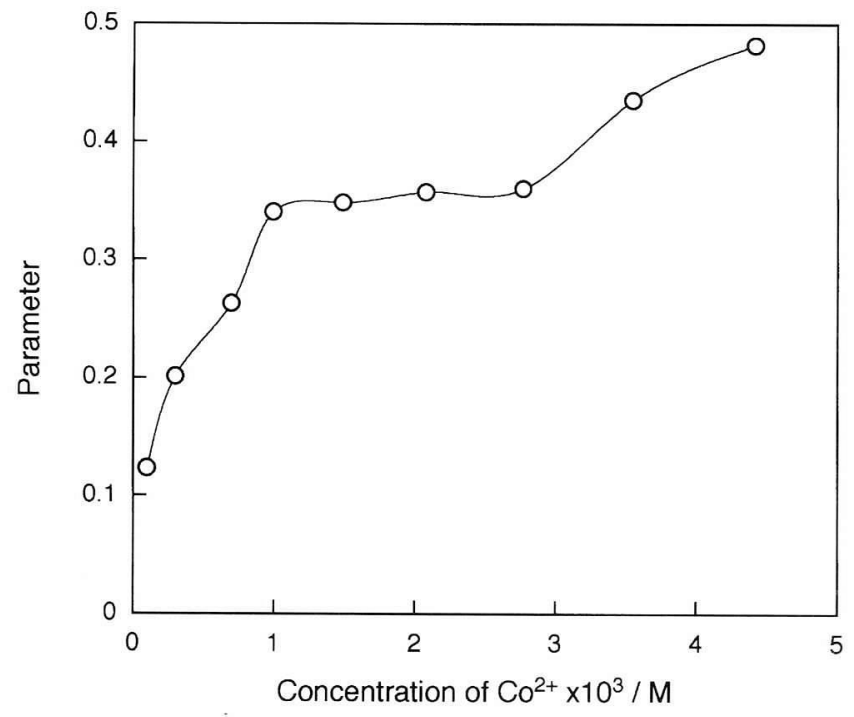

Figure 8 Sensing parameters of $2\left(5.0 \times 10^{-7} \mathrm{M}\right)$ in a $10 \mathrm{vol} \%$ DMF aqueous solution with variaous concentration of $\mathrm{CO}^{2+}$. 
Table 1 Binding constants $\left(\mathrm{K} / \mathrm{mol}^{-1} \mathrm{dm}^{3}\right)$ of 1 and $2\left(5.0 \times 10^{-7} \mathrm{M}, 25^{\circ} \mathrm{C}\right)$ in a $10 \% \mathrm{DMF}$ aquaous solution.

\begin{tabular}{ccc}
\hline Metal & $\mathbf{1}$ & $\mathbf{2}$ \\
\hline $\mathrm{Na}^{+}$ & $1566 \pm 90^{\mathrm{b})}$ & $935 \pm 56$ \\
$\mathrm{Li}^{+}$ & $351 \pm 16$ & $1986 \pm 83$ \\
$\mathrm{~K}^{+}$ & $1293 \pm 130$ & $754 \pm 54$ \\
$\mathrm{Cr}^{2+}$ & $541 \pm 49$ & $1176 \pm 76$ \\
$\mathrm{Co}^{2+}$ & $1266 \pm 102$ & $1443 \pm 56$ \\
$\mathrm{Ni}^{2+}$ & $1384 \pm 43$ & $2560 \pm 99$ \\
$\mathrm{Zn}^{2+}$ & $862 \pm 46$ & $2945 \pm 107$ \\
$\mathrm{Cd}^{2+}$ & $5179 \pm 300$ & $2999 \pm 122$ \\
$\mathrm{Al}^{3+}$ & $2286 \pm 162$ & $611 \pm 34$ \\
\hline
\end{tabular}

a) The $\mathrm{K}$ values were obtained from guest-induced fluorescence variations.

b) The statistical errors were values of standerd deviation assessed by guest-induced fluorescence variations.

and 2 for a couple of metal cations lined as their metal size order. Compound 1 detects $\mathrm{Na}^{+}$with the highest parameter and the sequence of the sensing paramete is $\mathrm{Na}^{+}>\mathrm{K}^{+}>\mathrm{Ni}^{2+}>\mathrm{Cd}^{2+}>\mathrm{Cr}^{2+}>$ $\mathrm{Al}^{3+}>\mathrm{Co}^{2+}=\mathrm{Zn}^{2+}>\mathrm{Li}^{+}$. It is suggested that sensing ability of 1 is not depended on metal cation size. In contrast, compounds 2 detects $\mathrm{Co}^{2+}$ with the highest parameter and the sequence of the sensing parameter of 2 is $\mathrm{Co}^{2+}>\mathrm{Ni}^{2+}>\mathrm{Na}^{+}>\mathrm{Zn}^{2+}>\mathrm{Li}^{+}>\mathrm{Cr}^{2+}=$ $\mathrm{Cd}^{2+}>\mathrm{Al}^{3+}>\mathrm{K}^{+}$. Decreasing the order of metal cation size of $\mathrm{Cd}^{2+}>\mathrm{Li}^{+}>\mathrm{Zn}^{2+}>\mathrm{Ni}^{2+}>\mathrm{Co}^{2+}$, sensing parameters of 2 increase, however, smaller metal sized cations such as $\mathrm{Cr}^{2+}$ and $\mathrm{Al}^{3+}$ are detected with lower sensing parameter than those metal cations such as $\mathrm{Cd}^{2+}$ to $\mathrm{Co}^{2+}$. It is recognized that sensing abilities of 2 are depended on metal cation size such as $\mathrm{Cd}^{2+}$ to $\mathrm{Co}^{2+}$ lined up, as

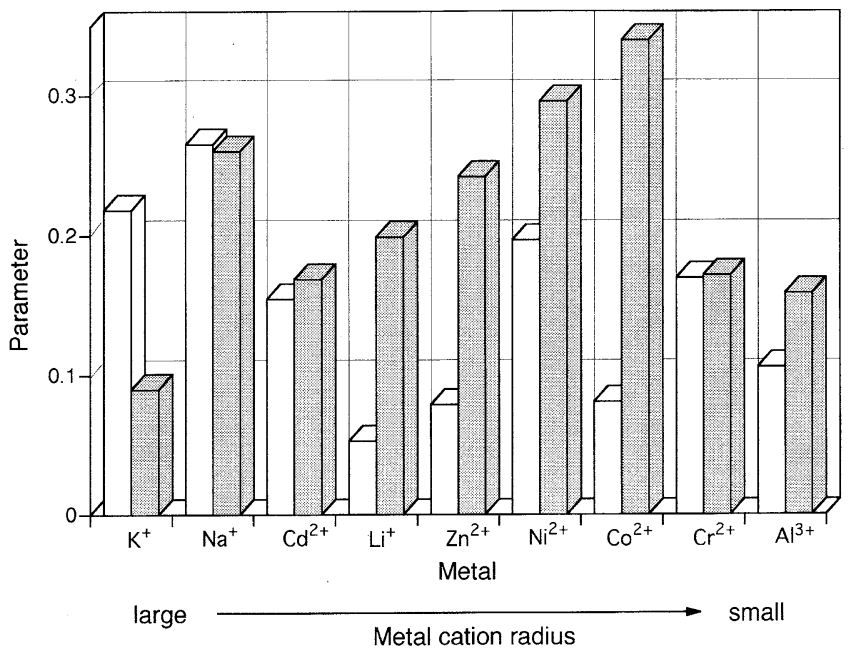

Figure 9 Sensitivity factors of $1(\square)$ and $2(\square)\left(5.0 \times 10^{-7} \mathrm{M}, 25^{\circ} \mathrm{C}\right)$ in a 10 vol.\% DMF aqueous solution for all metal cations examined $\left(1.0 \times 10^{-3} \mathrm{M}\right)$. shown in Figure 9. We obtained binding constant by using Equation (1) as reported previously. ${ }^{7,32,33}$

$$
\frac{1}{I_{\text {ex }} I_{\text {ex }}^{0}}=\frac{1}{\mathrm{a}[\mathrm{Host}]}+\frac{1}{\mathrm{a}[\mathrm{Host}] K} \times \frac{1}{[\text { Metal }]}
$$

Here, $I$ is the fluorescence intensity at $465 \mathrm{~nm}$ ( $I_{e x}$ for complex, $I_{\text {ex }}^{0}$ for the host alone), [Host] is the total host concentration, [G] is the total guest concentration, $a$ is a constant. The binding constants were obtained to examine the correlation between the fluorescence variations and the binding abilities of the hosts. The results are shown in Table 1. The order of the binding constants of the host for metal cations is not parallel with the order of the sensitivity factor. This means that the sensitivity value gives primary value to show how much familiar for the guest molecule examined at some concentration.

\section{Conclusion}

This study performed elucidation of metal sensory system based on fluorogenic mono- and bis-pyrene appended cavitands in aqueous solution, in which water-soluble cavitands could be synthesized for the first time. These compounds show association dimer in water rich solvent, whereas the association dimer formation was canceled or transformed in polar solvent. In an aqueous solution containing 10 vol.\% DMF, these cavitand derivatives recognized metal cations such as $\mathrm{Co}^{2+}, \mathrm{Ni}^{2+}, \mathrm{Na}^{+}$, and $\mathrm{Zn}^{2+}$ with high sensitivity. The decrement of pyrene excimer was used as a detecting parameter. This work has clarified that these pyreneappended cavitands compose supramolecule formation such as association dimer. We are now wrestling with self-folding system using compounds 1 and 2 as a molecular device for a nanoscale in the next generation of cavitand chemistry.

\section{Acknowledgements}

This study was supported by a Grant-in-Aid for Specially Promoted Research (No.404:Molecular Synchronization for Design of New Materials System) from the Ministry of Education, Science, Sport and Culture of Japan.

\section{References}

1. H. -J. Schneider and H. Dürr, Frontiers, Supramolecular Organic Chemistry and Photochemistry, VCH, Weinheim, 1991.

2. I. Aoki, T. Sasaki, S.Tsutsui, and S. Shinkai, "Molecular Design of Calix[4]arene-Based Fluorescent Hosts", Tetrahedron. Lett., 1992, 33, 89.

3. J. -M. Lehn, Supramolecular Chemistry, VCH, Weinheim, 1995.

4. M. Sato, M. Narita, N. Ogawa, and F. Hamada, "Fluorescent Choemo-Sensor for Organic Guests Based on Regioselectively Modified $6^{\mathrm{A}}, 6^{\mathrm{B}}-, 6^{\mathrm{A}}, 6^{\mathrm{C}}-$, and $6^{\mathrm{A}}, 6^{\mathrm{D}}-\mathrm{Bis}$-dansylglycine-modified $\beta$-Cyclodextrins", Anal. Sci., 1999, 15, 1199.

5. M. Narita, F. Hamada, M. Sato, I. Suzuki, and T. Osa, "Fluorescent Molecular Recognition and Sensing System of Bis-Dansyl Modified $\gamma$-Cyclodextrins", J. Incl. Phenom. Macro. Chem., 1999, 34, 421.

6. M. Narita, Y. Higuchi, F. Hamada, H. Kumagai, "Metal Sensor of Water Soluble Dansyl-modified Thiacalix[4]arenes", Tetrahedron Lett., 1998, 39, 8687.

7. Y. Higuchi, M. Narita, T. Niimi, N. Ogawa, F. Hamada, H. Kumagai, N. Iki, S. Miyano, and C. Kabuto, "Fluorescent 
Chemo-Sensor for Metal Cations Based on Thiacalix[4]arenas Modified with Dansyl Moieties at the Lower Rim", Tetrahedoron, 2000, 56, 4659.

8. J. R. Moran, S. Karbach and D. J. Cram, "Cavitands: Synthetic Molecular Vessels", J. Am. Chem. Soc., 1982, 104, 5826.

9. D. J. Cram, S. Karbach, H. E. Kim, C. B. Knobler, E. F. Maverick, J. L. Ericson, R. C. Helgeson, "Host-Guest Complexation. 46. Cavitands as Open Molecular Vessels Form Solvates", J. Am. Chem. Soc., 1988, 110, 2229.

10. D. J. Cram, J. Weiss, R. C. Helgeson, C. B. Knobler, A. E. Dorigo, and K. N. Houk, "Design, Synthesis, and Comparison of Crystal, Solution, and Calculated Structures within a New Family of Cavitands", J. Chem. Soc., Chem. Commun., 1988, 407.

11. E. Dalcanale, P. Soncini, G. Bacchilega, and F. Ugozzoli, "Slective Complexation of Neutral Molecules in Organic Solvents. Host-Guest Complexes and Cavitates between Cavitands and Aromatic Compounds", J. Chem. Soc., Chem. Commun., 1989, 500.

12. J. A. Bryant, M. T. Blanda, M. Vincenti, and D. J. Cram, "Shell Closure of Tetrabenzyl Chloride Cavitands with Tetrabenzylthiol Cavitands Provide Carceplexes in which One or Two Guest Molecules are Incarcerated", J. Chem. Soc., Chem. Commun., 1990, 1403.

13. R. C. Helgeson, C. B. Knobler and D. J. Cram, "A Tetrathiol Bowl-shaped Cavitand and a Derived Carceplex", J. Chem. Soc., Chem. Commun., 1995, 307.

14. C. von dem Bussche-Hunnefeld, D. Buhring, C. B. Knobler, and D. J. Cram, "Hemicarcerands with Interiors Potentially Capable of Binding Large Guests", J. Chem. Soc., Chem. Commun., 1995, 1085.

15. P. C. Helgeson, K. Peak, C. B. Knobler, E. F. Maverick, and D. J. Cram, "Guest-Assisted and Guest-Inhibited Shell Closures Provide Differently Shaped Carceplexes and Hemicarceplexes", J. Am. Chem. Soc., 1996, 118, 5590.

16. J. Yoon, C. Sheu, K. N. Houk, C. B. Knobler, and D. J. Cram, "Synthesis, Binding properties, and Structures of Seven New Hemicarcerands Each Composed of Two Bowls Bridged by Three Tetramethylenedioxy Groups and a Fourth Unique Linkage", J. Org. Chem., 1996, 61, 9323.

17. N. Chopra and J. C. Sherman, "A Bis (carceplex) from a Cyclic Tetramer of Cavitands", Angew. Chem. Int. Ed. Engl., 1997, 36, 1727.

18. D. M. Rudkevich, G. Hilmersson and J. Rebek Jr., "SelfFolding Cavitands", J. Am. Chem. Soc., 1998, 120, 12216.

19. B. S. Park, C. B. Knobler, C. N. Eid Jr. R. Warmuth, and D. J. Cram, "Chiral and somewhat hydrophilic hemicarceplexes", J. Chem. Soc., Chem. Commun., 1998, 55.20. R. Warmuch, "First innermolecular Diels-Alder reaction of $o$-benzyne inside a molecular container compound", J. Chem. Soc., Chem. Commun., 1998, 59.
21. H. Xi, C. L. D. Gibb, E. D. Stevens, and B. C. Gibb, "Deepcavity cavitands: synthesis and solid state atructure of host molecules possessing large bowl-shaped cavities", J. Chem. Soc., Chem. Commun., 1998, 1743.

22. L. R. MacGillivray, P. R. Diamente, J. L. Reid, and J. A. Ripmeester, "Encapsulation of two aromatics by a carcerandlike capsule of nanometer-scale dimensions", J. Chem. Soc., Chem. Commun., 2000, 359.

23. O. D. Fox, M. G. B. Drew, E. J. S. Wilknson, and P. D. Beer, "Cadminm- and zinc-directed assembly of nano-sized, resorcarene-based architectures which strongly bind $\mathrm{C}_{60} ", J$. Chem. Soc., Chem. Commun., 2000, 391.

24. C. L. D. Gibb, E. D. Stevens and B. C. Gibb, "The selfassembly of benzyl alcohol derived deep-cavity cavitands: a new, highly efficient moiety for irreversible assemblies" $J$. Chem. Soc., Chem. Commun., 2000, 363.

25. A. R. Renslo, F. C. Tucci, D. M. Rudkevich, and J. Rebek Jr., "Synthesis and Assembly of Self-Complementary Cavitands", J. Am. Chem. Soc., 2000, 122, 4573.

26. U. Lucking, F. C. Tucci, D. M. Rudkevich, and J. Rebek Jr, "Self-Folding Cavitands of Nanoscale Dimensions", J. Am. Chem. Soc., 2000, 122, 8880.

27. F. Hamada, S. Ito, M. Narita, and N. Nashirozawa, "Selective Chloromethylation of Cavitand at the Upper Rim and Induced Fit Type Complexation with Metal Cations by New Cavitands : Aza-Crown-Modified Cavitands", Tetrahedron Lett., 1999, 40, 1527.

28. There are a couple of examples bis pyrene modified synthetic receptors. a) K. R. A. S. Sandanayaka, T. D. James and S. Shinkai, "Two Dimensional Photoinduced Electron Transfer (PET) Fluorescence Sensor for Saccharides", Chem. Lett., 1995,503 . b) T. Jin, "A new $\mathrm{Na}^{+}$sensor based on intermolecular fluorescence energy transfer derived from calyx[4]arene", J. Chem. Soc., Chem. Commun., 1999, 2491.

29. U. Burkert and N. L. Allinger, "Molecular Mechanics", 1982, ACS Monograph 177, American Chemical Society, Washington, D.C.

30. M. J. Dudek and J. W. Ponder, "Accurate Modeling of the Intramolecular Electrostatic Energy of Proteins", J. Comput. Chem., 1995, 16, 791.

31. A. Ueno, I. Suzuki and T, Osa, "Host-Guest Sensory Systems for Detecting Organic Compounds by Pyrene Excimer Fluorescence" Anal. Chem., 1990, 62, 2461.

32. M. Narita, F. Hamada, I. Suzuki, and T. Osa, "Variations of Fluorescent molecular sensing for organic guests by regioselective anthranilate modified $\beta$ - and $\gamma$-cyclodextrin s", J. Chem. Soc., Perkin Trans 2, 1998, 2751.

33. M. Narita and F. Hamada, "The Synthesis of a fluorescent chemo-sensor system based on regioselectively dansyl-tosylmodified $\beta$ - and $\gamma$-cyclodextrins", J. Chem. Soc., Perkin Trans 2, 2000, 823. 